\title{
Ego-Depletion Promotes Altruistic Punishment
}

\author{
Yaozhong Liu, Na He, Kai Dou \\ School of Management, Jinan University, Guangzhou, China \\ Email: 13370126992@163.com
}

Received 14 October 2015; accepted 9 November 2015; published 12 November 2015

Copyright (C) 2015 by authors and Scientific Research Publishing Inc.

This work is licensed under the Creative Commons Attribution International License (CC BY). http://creativecommons.org/licenses/by/4.0/

c) (i) Open Access

\begin{abstract}
To explore whether psychological resource influences the altruistic punishment, Experiment 1 used the Stroop Task to manipulate participants' self-control resources and the rejection ratio of unfair proposals in the subsequent Ultimate Game was measured to reveal the effect of selfdepletion on altruistic punishment. The result of Experiment 1 showed that decline ratio of participants in the high-depletion group was significantly higher than that of participants in the low-depletion group. After manipulation of self-depletion with the Stroop task, participants in experiment 2 acted as the third-party who watched other two participants playing the Dictator Game and could use their own tokens to punish unfair proposals. The result of Experiment 2 showed that participants in the high-depletion group punished unfair proposals significantly more than counterparts in the low-depletion group. In sum, the results of these two experiments showed that ego depletion promoted altruistic punishment.
\end{abstract}

\section{Keywords}

Altruistic Punishment, Ego-Depletion, Inequality Aversion

\section{Introduction}

The news that employees reported the illegal operation of their companies and the general public reported the graft and corruption of government officials were relatively pervasive in our society today. Under most of the circumstances, reporters had to take the risk of losing jobs or damaging their personal profits. Although sacrificing time or money, they don't get any immediate or prospective return. However, this kind of pro-social behavior that transcends the rational-economic man hypothesis is extremely significant for the maintenance of trust and cooperation [1] [2]. This kind of pro-social behavior that punishes social-norm violators without immediate or potential gains, even with the sacrifice of one's own profit is called altruistic punishment [2]. The influential 
factors of altruistic punishment have received attention from numerous scholars and previous researches explored the influential mechanism of personality traits such as agreeableness [3], compassion [4], egalitarian motive [5] and physiological resource [6] such as serotonin on altruistic punishment while little research has explored the influence of psychological resource. Previous research proposed that altruistic punishment is automatic behavior model resulted from "inequality aversion" of human beings during the evolution process [7]. Individuals under ego-depletion are more inclined to conserve psychological resources which result in the commonly heavy reliance on routine and automatic processes [8]. So we proposed that ego-depletion may promote altruistic punishment and further explored the causal relationship between them based on recourse model and dual-system theory.

\subsection{Ego Depletion}

Self-control is the capacity of altering or inhibiting thoughts, emotions and behaviors to abide by social norms, values and morality standards [9]. The recourse model of self-control deems that just like the muscle of human beings feel tired after much exercise, the recourse of self-control is limited and repeated exercise of self-control leads to impaired performance on subsequent self-control tasks which is labelled ego-depletion [10] [11]. Behaviors of human beings are influenced by heuristic and analytical systems, the first one is fast, automatic and not influenced by self-control resources while the latter one is slow-processed, analytical and heavily depend on psychological resources [12]. Individuals under ego-depletion tend to heavily rely on routine and automatic process which means their behaviors are mainly influenced by heuristic system [8]. Most previous studies explored the negative sides of ego-depletion as humans influenced by heuristic system usually cannot inhibit selfish impulse and desire and abide by social norms. Humans under ego-depletion show more aggression as their capacity of inhibiting aggressive thoughts and behaviors decreased [13]. Ego-depletion also make them showed more dishonest and unethical behaviors for their own profits when faced with material temptation [14] [15].

\subsection{Altruistic Punishment}

Previous studies proposed that altruistic punishment is resulted from the automatic behavioral model of "inequality aversion" that humans are innately disgusted with unfair distribution [7] [16]. The negative emotions of anger and disgust after experience or witness unfairness are exactly the reasons of altruistic punishment [17]. The subjects in the experimental group of a study were practitioners of mediation which empathized on compassion, altruism and benevolence. As recipients of dictator game, subjects of experimental group felt less anger and showed significantly lower decline ratio than subjects of control group [4].

Previous studies usually used game paradigm involving real money to explore altruistic punishment. A study used public-recourse paradigm to corroborate the importance of altruistic punishment for cooperation [1]. Another study used the Ultimate Game to explore the influence of Social Value Orientation (SVO) on the refusal of unfair distribution proposal which is the indicator of altruistic punishment [18]. Third-party punishment was used to explore the mechanism of conflict between maximization of individual profit and fairness principle, the punishment of norm-violators with the cost of one's own payment was the measurement indicator of altruistic punishment [19].

\subsection{Ego-Depletion and Altruistic Punishment}

Many researches explored the negative effect of ego-depletion on individual's executive capacities and subsequent behaviors such as compared with subjects of low depletion group, subjects of high depletion group showed less trust on counterparts in the trust paradigm as the psychological resources of inhibition of suspicion and hesitation decreased [20]. Another study explored the influence of ego-depletion on the pro-social behavior of helping, the experiment result showed that the helping of subjects in the high depletion group decreased significantly [21]. However, recently some scholars have begun to explore the positive sides of ego depletion and impaired executive ability on individuals' behavioral decision-making. An experimental study found subjects of high depletion group were significantly more willing to make sacrifice in romantic relationship as individuals obsessed with romantic love usually have the strong impulse to give which is difficult to control for individuals of high depletion and impaired executive recourses [22].

Previous studies on the psychological mechanism of altruistic punishment proposed that the innate "inequality aversion" of human beings make them have the strong impulse to punish norm-violators which are stemmed from the intensified anger and disgust even with the sacrifice of one's own profits [7]. Besides, the inhibition 
capacity of individuals with impaired psychological recourses decreased [23]. Based on these, this study hypothesized that subjects in the high depletion group will show more altruistic punishment as the psychological recourses of inhibition of anger and punishment impulse decreased.

In experiment 1 , after the manipulation of ego-depletion, subjects participated in the Ultimate Game as recipients and the rejection ratio of unfair distribution proposal was analyzed to explore the causal relationship of these two variables. Some studies proposed that the reason why subjects in the experiment 1 showed altruistic punishment was that their personal profit was directly related with the distribution proposal [19] [24] [25]. To further explore whether individuals were willing to punish unfair distribution with the money sacrifice if themselves weren't involved in the proposal, subjects in the experiment 2 were merely third-party who watched others playing the Dictator Game and were able to punish the unfair proposer with their own money in every round. The punishment ratio of subjects in the experiment 2 was analyzed to further explore the relationship between these two variables.

\section{Experiment 1}

\subsection{Subjects}

40 post-graduate students that consisted of 20 male students and 20 female students were recruited by sending messages and posting advertisement. After the match of sex, subjects were randomly assigned to low and high depletion groups. The physiological visual condition of all subjects was suited for Stroop Task.

\subsection{Method}

\subsubsection{Experimental Design}

This experiment used the 2(ego-depletion: high, low) $\times 4$ (fairness degree: 60-40, 70-30, 80-20, 90-10) mixed experimental design with the ego-depletion as the between-subject variable of low and high two levels and fairness degree as the within-subject variable of 4 levels. The number dyad represents the money assigned to themselves and counterpart by the proposer, 50-50 were also randomly appeared in the computer screen during the experiment to increase the authenticity. The rejection rate of unfair distribution proposal in the Ultimate Game was the dependent variable.

\subsubsection{Experimental Task}

Ego-depletion task: Many previous studies indicated that the Stroop task can successfully manipulate individuals' psychological resources [14] [26]. The Stroop task of individuals in the high depletion group was 144 mismatch "meaning-color" stimulus (such as word blue with the color red) while the task of low depletion group was matching "meaning-color" stimulus (such as word blue in the color blue). Point of fixation was firstly appeared in the computer screen for $200 \mathrm{~ms}$ and four different color words were randomly appeared to which subjects had to respond as quickly as possible. Then feedback of response was appeared and $200 \mathrm{~ms}$ of blank screen were followed finally.

The Ultimate Game: The proposer gives a distribution proposal and the money will be assigned between them accordingly if the recipient agrees with it, otherwise neither of them gets money. When rejecting the distribution proposal, individuals make sacrifice although the norm-violator is punished which is at accordance with the definition of altruistic punishment. Figure 1 showed the procedure of the Ultimate Game which followed the

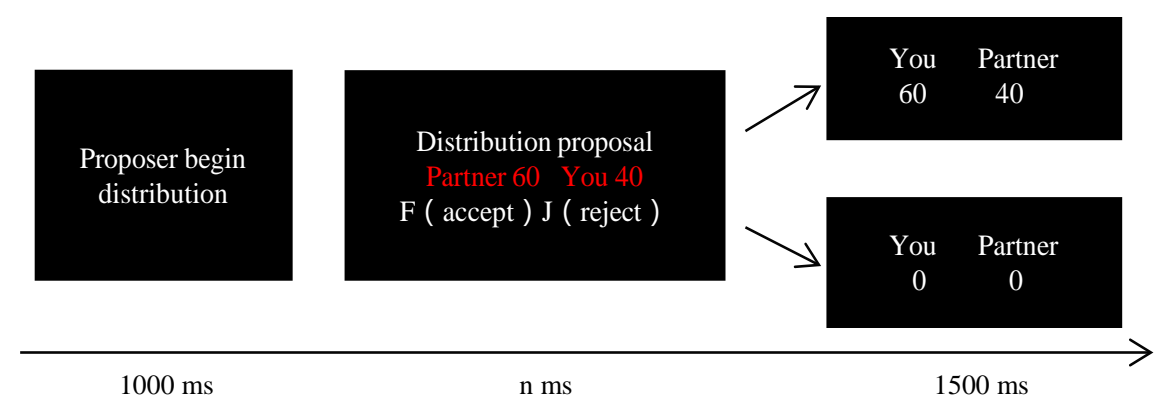

Figure 1. Procedure of the ultimate game. 
manipulation of ego-depletion. During the experiment procedure, "proposer begins distribution” was appeared firstly to reminder the subjects and the distribution proposal was subsequently appeared in the screen. Subjects then had to click the button to decide whether approve or reject the distribution proposal. The final screen showed the money they can get in this round respectively (see Figure 1). Once having arrived at the laboratory, subjects were told that another subject would stay in the neighborhood and participate in the experiment with them as a group, while in fact all distribution proposals would appear according to the computer program. The experiment was consisted of 16 rounds which include 6 fair rounds (50-50), 3 relatively unfair rounds (70-30) and 7 desperately unfair rounds (80-20, 90-10) [6].

\subsubsection{The Control of Extra Variables}

The trait self-control and mood may be the extra variables of this experiment which were measured during the experiment to control their influence on dependent variable and increase the internal validity.

(1) The Trait Self-Control Scale (TSC)

This scale was revised by Chinese scholars which include 13 items with high reliability $(\alpha=0.93)$ [27]. Before the experiment procedure, subjects had to finish this scale to overcome the influence of extra variables.

(2) Positive Affect and Negative Affect Scale (PANAS)

PANAS $(\alpha=0.65)$ was used to measure the mood of subjects when they finish the Stroop Task with the Likert five-points.

\subsubsection{Experiment Procedure}

With the arrival at the laboratory, participants firstly fill in the TSC and then randomly assigned to the high or low depletion group. To eliminate the influence of extra variables such as mood on subsequent behavioral decision-makings, subjects filled in the PANAS after the manipulation of psychological resources with the Stroop Task. Then instructions of the Ultimate Game appeared in the screen that emphasize the money amount accumulated in the 16 rounds with 100 yuan in each round would be converted to real money according to certain ratio which was the experiment reward and attendance fee. After the Ultimate Game, the accumulated money amount was converted to real money with the ratio of 1:100 and questions of subjects were answered patiently.

\subsection{Experiment Result and Analysis}

(1) Test of trait self-control

To explore whether the rejection ratio of unfair distribution proposals in the Ultimate Game was related to subjects' trait self-control, TSC was filled in once them arrived at the laboratory. The t-test of trait self-control scores of subjects in the high and low depletion group showed that there was no significant difference between these two groups $\left(t_{(38)}=-1.542, \mathrm{p}=0.13\right)$.

(2) Test of mood

To explore whether the decision-making in the Ultimate Game was influenced by the mood after the Stroop Task, the score of PANAS filled by subjects was analyzed. The t-test of PANAS of subjects in the high and low depletion group showed there is no significant difference between these two groups $\left(t_{(38)}=-1.106, \mathrm{p}=0.276\right)$.

(3) The influence of ego-depletion on altruistic punishment

With the level of depletion as the between-subject variable and fairness degree as the within-subject variable, ANOVA was used to explore the main and interaction effect of these two variables. The result showed that the main effect of ego-depletion is significant $\left(F_{(1,38)}=4.56, \mathrm{p}=0.04, \eta^{2}=0.11\right)$. Figure 2 indicated that subjects in the high-depletion group showed more altruistic punishment at all levels of fairness. Besides, the main effect of within-subject was also significant which showed with the rise of unfairness degree, the rejection ration was correspondingly higher $\left(\mathrm{F}_{(3,114)}=46.267, \mathrm{p}<0.01, \eta^{2}=0.54\right)$.

\section{Experiment 2}

Previous studies showed that as recipients of distribution proposals whose money payment was directly related with the proposal, subjects showed altruistic punishment because their personal profits was damaged which resulted in subsequent anger and disgust [19] [24] [25]. However, some individuals who did not experience inequality but witness others being treated unfairly may also feel negatively and were willing to punish norm-violators even with the sacrifice of their personal profits. A study used fMRI to scan the brain of subjects who showed the third-party punishment and found the brain of nucleus accumbens that process reward information 


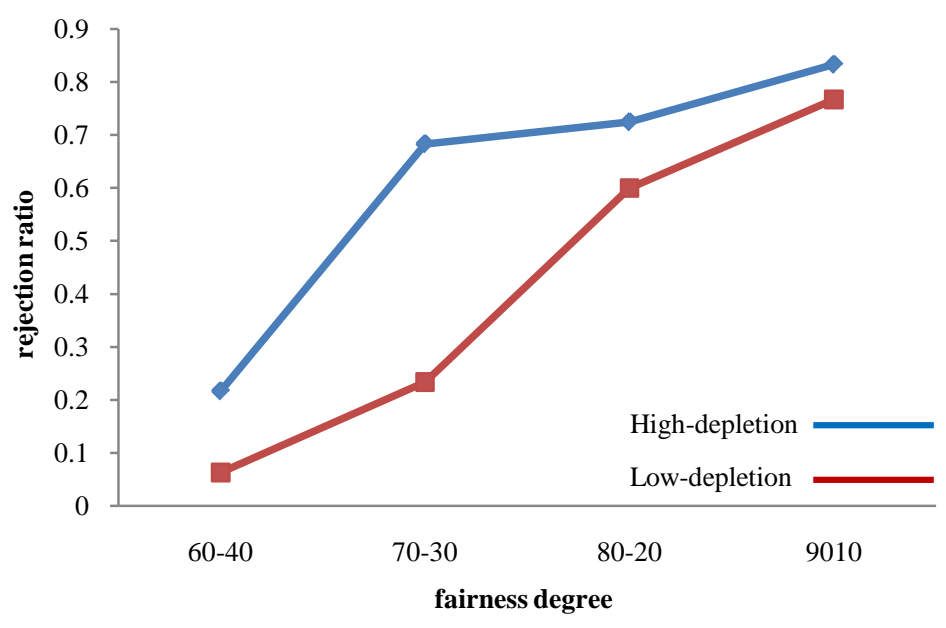

Figure 2. Rejection ratio of unfair proposals of subjects in the high and low depletion group.

was activated and the motivational mechanism of both second and third party punishments are cognition-emotionmotivation system only with the difference of amount [25].

To further explore whether subjects would show altruistic punishment when their personal profits was not directly related with the distribution proposal, subjects acted as third-party who witness other two players play the Dictator Game and can use their own money in the account to punish the proposals in the Game.

\subsection{Subject}

Another 20 male and 20 female postgraduate students whose physiological condition met the requirements of this experiment were recruited. Subjects were randomly assigned to low and high depletion group after the match of sex.

\subsection{Method}

\subsubsection{Experiment Design}

Experiment 2 was the 2(ego depletion: high, low) $\times 3$ (fairness degree: fair, unfair, desperately unfair) mixed experimental design with the between-subject variable of depletion and within-subject variable of fairness degree of distribution proposal. The dependent variable was the punishment ration of subjects acting as third-party who watched other two players playing the Dictator Game.

\subsubsection{Experiment Task}

(1) Ego depletion: Stroop task was used to manipulate the self-control resources which was the same as experiment 1.

(2) The Dictator Game: This is also the Game Paradigm that distribute money among proposer and recipient. What is different from the Ultimate Game is recipient in this game have no right to reject the proposal which means the recipient has to accept the money amount assigned by the proposer. After the understanding of the principles of Dictator Game, subjects were told that other two subjects would play this game in the neighborhood and he would watch the whole process and have the right to punish the proposer with their own tokens in every round. Specifically, the other two players split the token of 100 yuan and the subject had the token of 50 yuan, 15 yuan of which could be used to punish the proposer in every round. The decision of punishment meant the money amount that the proposers assigned to themselves decreased the triple of 15 yuan. Besides, the principle of experiment reward that tokens accumulated in their account would be converted to real money with the ratio of 1:100 was emphasized. Figure 3 showed the procedure of the Third-party punishment which followed the manipulation of ego-depletion. "Proposer begins distribution" appeared in the center of the computer screen for $100 \mathrm{~ms}$ as the reminder of beginning. The second screen appeared the distribution proposal of proposer in the Dictator Game and click choice of punishment or not. The amount of money assigned to each party in the Dictator 

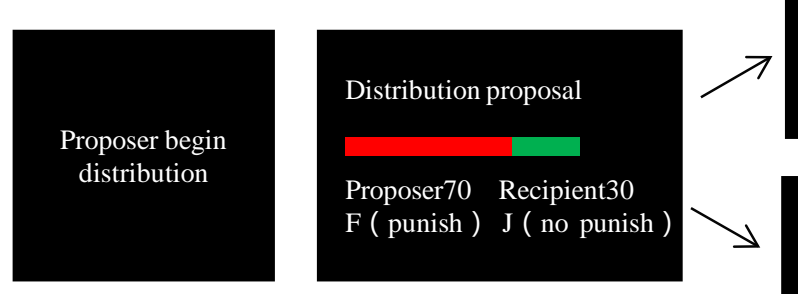

Distribution Result

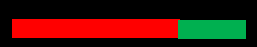

Proposer 70 Recipient30

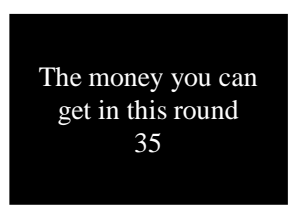

Proposer 25 Recipient30

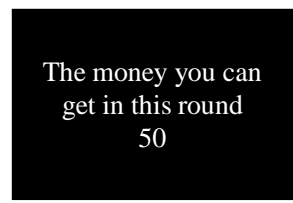

$2000 \mathrm{~ms}$

Figure 3. Procedure of the third-party punishment.

Game would appear in the computer screen for $2000 \mathrm{~ms}$ after the click of subjects and the token that the subjects could get in this round appeared in the final screen for $2000 \mathrm{~ms}$ (see Figure 3).

\subsubsection{The Control of Extra Variables}

The trait self-control and mood were extra variables that may confound with the independent variables. Corresponding scales were used to measure these and subsequent statistical analysis would eliminate the influence of them to increase the internal validity of experiment design.

\subsubsection{Experiment Procedure}

Subjects were instructed to fill in the TSC once the arrival at the laboratory and finish the corresponding random assignment of group. To eliminate the influence of extra variables when making behavioral decision-making, subjects were told to fill in the PANAS after the Stroop task. Principles of the Dictator Game appeared in the computer screen and corresponding quiz appeared to check the understanding of these. Subjects were then told other two subjects would play this Game in the neighborhood and they would watch the whole game process as the third party and be able to use their own toke to punish the unfair proposers. The tokens accumulated during the experiment process were converted to real money with the ration of 1:100 as the experiment reward and questions of subjects about the experiment were answered and thanks were given for their attendance and support.

\subsection{Experiment Result and Analysis}

(1) Trait self-control

To test whether subjects' punishment ratio of unfair distribution proposals as third-party is related with their trait self-control, subjects were instructed to fill in the TSC. The t-test of the scores of this scale of two groups showed no statistically significant difference $(t(38)=-1.542, \mathrm{p}=0.131)$.

(2) Mood

The t-test of the PANAS scale of high and low depletion groups showed no significant difference of the positive moon $(t(38)=-1.547, \mathrm{p}=0.13)$ and negative $\operatorname{mood}(t(38)=0.859, \mathrm{p}=0.396)$.

(3) The influence of ego-depletion on altruistic punishment

The result of the ANAVA analysis with the ego-depletion as the between-subject variable and fairness degree as the within-subject variable showed the main effect of both variables were significant. The main effect of ego-depletion was significant $\left(\mathrm{F}(1,37)=4.401, \mathrm{p}=0.02, \eta^{2}=0.13\right)$ and punishment ration of high-depletion group was higher than that of low-depletion group at every fairness degree which was indicated from the picture below. Besides, the main effect of fairness degree was also significant $\left(F(2,74)=129, p<0.01, \eta^{2}=0.79\right)$ and with the rise of the degree of unfairness, the punishment ration of third-party subjects became higher. The interaction effect of these two variables was not statistically significant.

\section{General Discussion}

The result of experiment 1 showed that the punishment ration of subjects in the high-depletion group was sig- 
nificantly higher than that of low-depletion group at all levels of fairness degree. The result of experiment 2 showed that as the third-party who watched the others playing the Dictator Game, most of the subjects in this experiment showed altruistic punishment even with the sacrifice of their personal gains. Besides, comparing with the subjects in the low-depletion group, subjects in the high-depletion group showed more altruistic punishment which were consistent with the hypothesis that ego-depletion promotes altruistic punishment.

The results of these two experiments confirmed the hypothesis which may because the psychological resources of anger and punishment impulse inhibition of high-depletion group were less than subjects in the low-depletion group who had more resources to "swallow" anger and punishment impulse. This may indicate that the punishment of equality-violation is an automatic behavioral tendency which may more incline to happen when the individuals' psychological recourses were impaired.

From the perspective of evolutionary psychology, humans gradually develop the innate disgust of unfairness and brain regions that are related with processing of reward-related information such as nucleus accumbens and Dorsal striatum are activated once the norm-violation behaviors are punished. Besides, some neuroscientific studies in this field offered physiological evidence for our hypothesis, a study revealed that the unfair proposals would activate two brain regions, one of them was anterior insula which was related with negative emotions such as anger and disgust, the other one was dorsolateral prefrontal cortex which was related with the focus and achievement of goals which meant the maximization of personal profits [17]. The ventromedial prefrontal cortex is related with emotion regulation and the study found the impairment of this brain region made subjects' inhibitive capacity of negative emotion decreased and showed more rejection of unfair proposals in the Ultimate Game [28]. These two neuroscientific studies offered physiological evidence for our study that the acceptance of unfair proposals was related with brain regions that were responsible for execution and the rejection was related with brain regions that were related with emotion, instinct and automation. This evidence to a certain degree supported the notion that punishment of unfairness was automatic behavior model developed during the evolution process.

The experiment results can be further explained with the dual-system theory that individuals' decision making is influenced by heuristic system which is fast, automatic and insensitive to psychological resources and analytical system which is reflective, slow and sensitive to self-control resources [12]. Self-control resources are necessary for individuals' executive capacities and recourses depletion of the previous task makes them inclined to preserve psychological resources and process information routinely and automatically. The behavioral decisionmaking of individuals under ego-depletion is more influenced by heuristic system as the temporary depletion of recourses makes the analytical system been inhibited.

This study extended the psychological mechanism of altruistic punishment with the subjects participated in as the second and third party. Besides, most of previous studies explored the negative influence of ego-depletion on behavioral decision-making while the result of this study showed that the ego-depletion promotes the prosocial behavior of altruistic punishment.

There are still limits in this study such as to increase the external validity, the tokens accumulated in this experiment were directly related with subjects' experiment reward. However, the decision-making of subjects was still influenced by the amount of the money and experiment environment.

\section{References}

[1] Fehr, E. and Gachter, S. (2002) Altruistic Punishment in Humans. Nature, 415,137-140. http://dx.doi.org/10.1038/415137a

[2] Lergetporer, P., Angerer, S., Glätzle-Rützler, D. and Sutter, M. (2013) Third-Party Punishment Increases Cooperation in Children through (Misaligned) Expectations and Conditional Cooperation. Proceedings of the National Academy of Sciences of the United States of America, 19, 6916-6921.

[3] Roberts, S.C., Vakirtzis, A., Kristjánsdóttir, L. and Havlíček, J. (2013) Who Punishes? Personality Traits Predict Individual Variation in Punitive Sentiment. Evolutionary Psychology, 11, 186-200. http://dx.doi.org/10.1177/147470491301100117

[4] McCall, C., Steinbeis, N., Ricard, M. and Singer, T. (2014) Compassion Meditators Show Less Anger, Less Punishment, and More Compensation of Victims in Response to Fairness Violations. Frontiers in Behavioral Neuroscience, 8, 424-432. http://dx.doi.org/10.3389/fnbeh.2014.00424

[5] Fowler,J. H., Johnson, T. and Smirnov, O. (2005) Human Behaviour: Egalitarian Motive and Altruistic Punishment. Nature, 433, E1-E3. http://dx.doi.org/10.1038/nature03256

[6] Crockett, M.J., Clark, L., Liberman, M.D., Tabibnia, G. and Robbins, T.W. (2010) Impulsive Choice and Altruistic 
Punishment Are Correlated and Increase in Tandem with Serotonin Depletion. Emotion, 10, 855-862. http://dx.doi.org/10.1037/a0019861

[7] Bowles, S. and Gintis, H. (2004) The Evolution of Strong Reciprocity: Cooperation in Heterogeneous Populations. Theoretical Population Biology, 65, 17-28. http://dx.doi.org/10.1016/j.tpb.2003.07.001

[8] Baumeister, R.F., Muraven, M. and Tice, D.M. (2000) Ego Depletion: A Resource Model of Volition, Self-Regulation, and Controlled Processing. Social Cognition, 18, 130-150. http://dx.doi.org/10.1521/soco.2000.18.2.130

[9] Baumeister, R.F., Vohs, K.D. and Tice, D.M. (2007) The Strength Model of Self-Control. Current Directions in Psychological Science, 16, 351-355. http://dx.doi.org/10.1111/j.1467-8721.2007.00534.X

[10] Baumeister, R.F., Bratslavsky, E., Muraven, M. and Tice, D. (1998) Ego Depletion: Is the Active Self a Limited Resource? Journal of Personality and Social Psychology, 74, 1252-1265. http://dx.doi.org/10.1037/0022-3514.74.5.1252

[11] Hagger, M.S., Wood, C., Stiff, C. and Chatzisarantis, N.L.D. (2010) Ego Depletion and the Strength Model of SelfControl: A Meta-Analysis. Psychological Bulletin, 136, 495-525. http://dx.doi.org/10.1037/a0019486

[12] Ferreira, M.B., Garcia-Marques, L., Sherman, S.J. and Sherman, J.W. (2005) Automatic and Controlled Components of Judgment and Decision Making. Journal of Personality and Social Psychology, 91, 797-813. http://dx.doi.org/10.1037/0022-3514.91.5.797

[13] DeWall, C.N., Baumeister, R.F., Stillman, T.F., Tyler, T.F. and Gailliot, M.T. (2007) Violence Restrained: Effects of Self-Regulation and Its Depletion on Aggression. Journal of Experimental Social Psychology, 43, 62-76. http://dx.doi.org/10.1016/j.jesp.2005.12.005

[14] Mead, N.L., Baumeister, R.F., Gino, F., Schweitzer, M.E. and Ariely, D. (2009) Too Tired to Tell the Truth: SelfControl Resource Depletion and Dishonesty. Journal of Experimental Social Psychology, 45, 594-597. http://dx.doi.org/10.1016/j.jesp.2009.02.004

[15] Gino, F., Schweitzer, M.E., Mead, N.E. and Ariely, D. (2011) Unable to Resist Temptation: How Self-Control Depletion Promotes Unethical Behavior. Organizational Behavior and Human Decision Processes, 115, 191-203. http://dx.doi.org/10.1016/j.obhdp.2011.03.001

[16] Fehr, E. and Schmidt, K.M. (1999) A Theory of Fairness, Competition, and Cooperation. The Quarterly Journal of Economics, 114, 817-868. http://dx.doi.org/10.1162/003355399556151

[17] Sanfey, A.G., Rilling, J.K., Aronson, J.A., Nystrom, L.E. and Cohen, J.D. (2003) The Neural Basis of Economic Decision-Making in the Ultimatum Game. Science, 300, 1755-1758. http://dx.doi.org/10.1126/science.1082976

[18] Karagonlar, G. and Kuhlman, D.M. (2013) The Role of Social Value Orientation in Response to an Unfair Offer in the Ultimatum Game. Organizational Behavior and Human Decision Processes, 120, 228-239. http://dx.doi.org/10.1016/j.obhdp.2012.07.006

[19] Qu, L.L., Dou, W., You, C. and Chen, Q. (2014) The Processing Course of Conflicts in Third-Party Punishment: An Event-Related Potential Study. PsyCh Journal, 3, 214-221. http://dx.doi.org/10.1002/pchj.59

[20] Ainswortha, S.E., Baumeistera, R.F., Ariely, D. and Vohs, K.D. (2014) Ego Depletion Decreases Trust in Economic Decision Making. Journal of Experimental Social Psychology, 54, 40-49. http://dx.doi.org/10.1016/j.jesp.2014.04.004

[21] Dewall, C.N., Baumeister, R.F., Gailliot, M.T. and Maner, J.K. (2008) Depletion Makes the Heart Grow Less Helpful: Helping as a Function of Self-Regulatory Energy and Genetic Relatedness. Personality and Social Psychology Bulletin, 34, 1653-1662. http://dx.doi.org/10.1177/0146167208323981

[22] Righetti, F., Finkenauer, C. and Finkel, E.J. (2013) Low Self-Control Promotes the Willingness to Sacrifice in Close Relationships. Psychological Science, 24, 1533-1540. http://dx.doi.org/10.1177/0956797613475457

[23] Baumeister, R.F. (2014) Self-Regulation, Ego Depletion, and Inhibition. Neuropsychologia, 65, 313-319. http://dx.doi.org/10.1016/j.neuropsychologia.2014.08.012

[24] Marijke, C.L., Eric, V.D. and Ilja, V.B. (2012) Punishing and Compensating Others at Your Own Expense: The Role of Empathic Concern on Reactions to Distributive Injustice. European Journal of Social Psychology, 42, 135-140. http://dx.doi.org/10.1002/ejsp.872

[25] Strobel, A., Zimmermann, J., Schmitz, A., Reuter, M., Lis, S., Windmann, S. and Kirsch, P. (2011) Beyond Revenge: Neural and Genetic Bases of Altruistic Punishment. NeuroImage, 54, 671-680. http://dx.doi.org/10.1016/j.neuroimage.2010.07.051

[26] Dou, K., Nie, Y.G., Wang, Y.J. and Li, J.B. (2014) Ego Depletion Promotes Risk-Taking. Journal of Psychological Science, 37, 150-155.

[27] Tan, S.H. and Guo, Y.Y. (2008) Revision of Self-Control Scale for Chinese College Students. Chinese Journal of Clinical Psychology, 16, 468-470.

[28] Koenigs, M. and Tranel, D. (2007) Irrational Economic Decision-Making after Ventromedial Prefrontal Damage: Evidence from the Ultimatum Game. The Journal of Neuroscience, 27, 951-956. http://dx.doi.org/10.1523/JNEUROSCI.4606-06.2007 